\title{
Children's CBT skills, metacognition, empathy, and theory of mind
}

Article

Accepted Version

Jones, J., Souchay, C., Moulin, C., Reynolds, S. and Adlam, A.-L. (2019) Children's CBT skills, metacognition, empathy, and theory of mind. Journal of Children's Services, 14 (1). pp. 16-26. ISSN 1746-6660 doi: https://doi.org/10.1108/JCS-122017-0052 Available at https://centaur.reading.ac.uk/80329/

It is advisable to refer to the publisher's version if you intend to cite from the work. See Guidance on citing.

To link to this article DOI: http://dx.doi.org/10.1108/JCS-12-2017-0052

Publisher: Emerald

All outputs in CentAUR are protected by Intellectual Property Rights law, including copyright law. Copyright and IPR is retained by the creators or other copyright holders. Terms and conditions for use of this material are defined in the End User Agreement.

\section{www.reading.ac.uk/centaur}

\section{CentAUR}

Central Archive at the University of Reading

Reading's research outputs online 


\section{Children's CBT skills, Metacognition, Empathy, and Theory} of Mind

\begin{tabular}{r|r|r|}
\hline \hline Mournal: & Journal of Children's Services \\
Manuscript Type: & $\begin{aligned} \text { JCS-12-2017-0052.R1 } \\
\text { Keywords: }\end{aligned}$ & $\begin{array}{l}\text { Cognitive Behavioural Therapy, Metacognition, Empathy, Theory of Mind, } \\
\text { Development, Children }\end{array}$ \\
\hline
\end{tabular}


Metacognition, Empathy, and Child CBT

\begin{abstract}
$\underline{\text { Abstract }}$
Purpose - Cognitive Behavioural Therapy (CBT) is an evidence based treatment for common mental health problems that affect children, young people, and adults. The suitability of CBT for children has been questioned because it requires children to think about their thoughts, feelings, and behaviours. The aim of this study was to investigate which cognitive and affective capacities predict children's ability to relate thoughts, feelings, and behaviours.

Design/methodology/approach - Fifty nine typically developing children aged between $\quad 8-11$ years took part in the study. CBT skills were assessed on a story task that required children to relate the character's thoughts to their feelings and behaviours. Children also completed an assessment of IQ, a feeling-of-knowing metamemory task that assessed metacognition, and a higher-order Theory of Mind (ToM) task. Furthermore, parents rated their child's empathy on the Children's Empathy Quotient.
\end{abstract}

Findings - Children demonstrated high levels of CBT skills, metacognition, and ToM. CBT skills were significantly predicted by metacognition and empathy, but not ToM.

Originality/value - The findings suggest that CBT is developmentally appropriate for $8-11$ year old children; however, young children and children with mental health problems may have impaired metacognition and CBT skills. Metacognition and empathy may moderate the efficacy of child CBT and warrant further investigation in clinical trials.

Keywords: Cognitive Behavioural Therapy, Metacognition, Empathy, Theory of Mind, Children

Article Type: Research Paper 
Metacognition, Empathy, and Child CBT

\section{$\underline{\text { Introduction }}$}

Cognitive Behavioural Therapy (CBT) seeks to address maladaptive behaviours and psychological distress by altering the cognitive processes and behaviours that sustain them. During therapeutic sessions, patients are required to participate in complex dialogue about their thoughts and feelings. To make this accessible to children, abstract concepts may be conveyed using concrete examples, stories, and visual imagery (e.g. Stallard, 2002a).

Reviews have concluded that CBT is an effective treatment for childhood and adolescent depression (Arnberg and Öst, 2014; Watanabe et al., 2007) and anxiety (James et al., 2015). However, approximately $40 \%$ of children with anxiety (James et al., 2015) and 50\% of children with depression (Watanabe et al., 2007) still meet diagnostic criteria following treatment. This may partly be because some children's cognitive and affective abilities are not sufficiently developed to fully engage with the therapeutic exercises (see Grave and Blissett, 2004, for a discussion). Further, when therapies have been shown to be effective, concerns have been raised over whether this is due to behavioural components and increased parental involvement, rather than cognitive restructuring (see Stallard, 2002b, for a review). To engage with cognitive restructuring, children must have developed the capacity to think about their thoughts, feelings and behaviours, and how they are related. Quakley (2001) designed two tasks that imitate the activities given to children receiving CBT. The 'discrimination task' requires participants to sort sentences containing a thought, feeling, or behaviour into the appropriate boxes. At the age of four, children begin to show some ability to discriminate thoughts, feelings and behaviours, given appropriate visual cues (Quakley et al., 2004), and by the age of seven children can complete this task proficiently (Quakley et al., 2003). The 'linking task' requires children to listen to a story and make associations between the protagonist's thoughts and their feelings and behaviours. Between five to seven years, children show some capacity to link thoughts to feelings, and to generate post-event attributions (Doherr et al., 2005). Similarly, whilst five year old children have a poor understanding of the relationship between thoughts and feelings, eight year olds understand that a thought can cause a sudden change in emotion and that sadness is normally associated with sad thoughts (Flavell et al., 2001). Thus, by the age of eight, children have a basic understanding of the relationship between thoughts, feelings and behaviours. 
The ability to think about one's own thoughts and feelings may largely depend on the development of metacognition and theory of mind (Quakley et al., 2004), which are closely related to executive functioning (Fernandez-Duque et al., 2000). Metacognition is the process of thinking about one's own thinking and it begins to develop in early childhood (Flavell et al., 2000). It has been suggested that metacognition is required to engage in CBT because it encompasses self-observation and self-evaluation (Grave and Blissett, 2004). At a basic level, one must know what they are thinking, feeling or doing, in order to discriminate between different thoughts, feelings or behaviours. Furthermore, one must have the capacity to understand how their thoughts, feelings and behaviours are related; for instance, how one's negative feelings and behaviours might be maintained by their maladaptive thought patterns. In fact, metacognition itself is a target for some CBT interventions given the role it can play in the maintenance of mood disorders. For example, Wells' metacognitive focused CBT primarily aims to modify metacognitive beliefs about worry in generalised anxiety disorder, rather than the worries themselves (Wells and King, 2006), and has been adapted for children (Esbjørn et al., 2015). In addition, mindfulness-based training aims to enhance metacognitive awareness when preventing relapse of depression (Crane et al., 2010).

Metacognition broadly concerns thinking about thinking (Flavell, 1979) and is a complex construct that is not directly observable. Assessments (see Lai, 2011, for a summary) have often focussed on a particular aspect of metacognition, such as metamemory. Metamemory is the awareness of one's memory contents (i.e. monitoring) and the use of strategies to improve memory (i.e. regulation; Nelson, 1990). The feeling-of-knowing paradigm (Hart, 1965) tests participants' ability to gauge the contents of memory, and the subsequent retrievability of currently inaccessible material. Previous research (e.g. Koriat, 1993) has shown that the feeling-of-knowing relies on a complex set of problem solving and epistemic processes that allow one to accurately gauge which non-recalled items will nonetheless be recognised at a later phase in the experiment. Thus, this paradigm measures the online ability to monitor mental operations and contents. Metamemory has also been associated with individual differences in executive functions (Mäntylä et al., 2010; Souchay and Isingrini, 2004), which may further support children's ability to relate thoughts to feelings and behaviours. A closely related cognitive system to metacognition is theory of mind (ToM). As originally defined, ToM is the ability to attribute mental states to oneself and others (Premack and 
Metacognition, Empathy, and Child CBT

Woodruff, 1978). These pioneering researchers explain that it is termed a theory because mental states are not directly observable and because ToM can be used to predict the behaviours of others. It is perhaps for this second reason that ToM has been intensely investigated in the domain of social cognition. Thus, a large proportion of the literature has only assessed attributions of mental states to others using methods such as the 'false-belief' task (Wimmer and Perner, 1983). Understanding the mental states of others is also important for child CBT because therapeutic exercises can require children to think about the thoughts and feelings of characters in various scenarios (e.g. Stallard, 2002a). Ultimately, this is to encourage the children to think about themselves in the same way.

Two theories have sought to explain how we read the minds of others (Gallese and Goldman, 1998). 'Theory theory' is closely related to ToM. It posits that we reason the mental states of others and predict their behaviour by using a set of general laws that relate mental states to external stimuli and behaviour (Gopnik and Wellman, 1992). 'Simulation theory' is related to empathy; the capacity to share in the feelings of others (Singer, 2006). This theory postulates that we can imagine ourselves in the position of other people and predict their mental states and behaviour by employing our own cognitive systems to imagine how we would feel or behave (Gallese and Goldman, 1998; Goldman, 1989).

\section{The Current Study}

This study aims to investigate the relationship between metacognition, ToM, empathy, and children's CBT skills. By the age of eight, children are aware of their cognitions (Flavell et al., 2000) and partially aware of how their thoughts and feelings are related (Flavell et al., 2001). Children have an advanced ToM by the age of 10 (Liddle and Nettle, 2006), meaning that they can infer what someone knows about another person's beliefs (second-order ToM) and what a third person may know about that (third-order ToM). The current study will examine whether these cognitive and affective capacities are related in a sample of children aged 8-11 years old. To assess CBT skills, children will complete the thought-feeling and thought-behaviour linking task (Quakley, 2001), as well as measures of ToM, metamemory and empathy. It has been suggested that the capacity to think about thoughts, feelings and behaviours is associated with metacognition and ToM (Grave and Blissett, 2004; Quakley et al., 2004). Therefore, it is hypothesised that metamemory and ToM will predict children's 
Metacognition, Empathy, and Child CBT

ability to link thoughts to feelings and behaviours over and above IQ, which is a measure of general cognitive ability. The findings of the study may identify important prerequisites of chid CBT, which may lead to recommendations for assessment and inform treatment decisions and delivery.

\section{Method}

\section{Participants}

Fifty-nine typically developing children took part in the study. The children were aged 8 to 11.83 years $(M=9.62, S D=1.07)$. The sample consisted of $28(48 \%)$ boys and $31(52 \%)$ girls. Fifty children (85\%) were White British, three were British Mixed Race and one was White European; five responses were missing. All participants spoke English as their first language. Children with a learning disability, history of head injury, pervasive developmental disorder, autistic spectrum condition, or previous contact with mental health services (see Reynolds et al., 2006) were excluded from the study.

\section{Procedure and Materials}

The testing sessions were one-to-one for approximately 90 minutes and regular breaks were offered during this time. Tasks were administered according to standard instructions (see cited studies below) and a standard test order was applied to reduce interference effects and maintain motivation.

\section{Thought-to-Feeling and Thought-to-Behaviour Linking Task:}

The linking task measured children's ability to understand another child's feelings or actions in relation to their thoughts (Quakley, 2001). The experimenter read aloud eight brief stories about different children and presented accompanying picture cards (see Figure 1). Each story centred on an event and how the protagonist felt or acted in response to this event. Later in the story, there was a cue that served as a reminder about the past event, which then caused the protagonist to feel or act in the same way as before. Participants were asked why the protagonist felt or acted the way they did. To score full marks participants had to mention the 
Metacognition, Empathy, and Child CBT

past event, the cue, and that the protagonist was thinking about the event (e.g. remembered). If incomplete responses were given, the experimenter would ask prompting questions.

Insert Figure 1 here.

Feeling-of-Knowing Metamemory Task:

This task was chosen to operationalise individual differences in metamemory and metacognition. Feeling-of-knowing has been shown to predict subsequent recognition (Hart, $1965)$ and previous tasks have been shown to have high test-retest reliability (.90; Nelson and Narens, 1980). The task follows four stages: study, cued-recall, feeling-of-knowing judgment, and recognition (Wojcik et al., 2013). Participants studied 20 word pairs that were presented one at a time on a computer screen for five seconds and simultaneously read aloud by the experimenter. The word pairs contained a cue word in lower case letters and a target word in upper case letters (e.g. 'chain' - 'ADVICE'). The matrix reasoning subtest was administered immediately after the presentation of the stimuli for five minutes and served as a distracter task. Children who did not finish the matrix reasoning subtest within five minutes completed it at the end of the metamemory task.

In the next phase, participants were presented with the cue words one-by-one. They were then asked two questions: "Can you remember the word that went with 'chain'?" and, "Would you be able to recognise that word if you were given four options?". Participants attempted to recall the target word before making a feeling-of-knowing judgement that was either 'Yes' or 'No'. Only those words which participants failed to recall were included in the analysis of metamemory performance (see Hart, 1965).

In the final phase, participants were presented with the cue words in the same order again. This time, four words, all in upper case, were presented beneath the cue. These included the correct target word and three previously unseen distracter words, which were not semantically related to the target word. Participants were instructed to select which word had been previously presented with the cue word. The main task was preceded by a practice run with three word pairs. 
Metacognition, Empathy, and Child CBT

\section{Higher-Order ToM Task:}

This task is an extension of the widely used false-belief paradigm (Wimmer and Perner, 1983) that was chosen to measure individual differences in zero- to fourth-order ToM.

Previous evidence suggests that this task has construct validity as performance has been associated with teacher ratings of children's social competence (Liddle and Nettle, 2006). Participants were told five different stories involving multiple characters in each. After each story the children were asked four questions (Liddle and Nettle, 2006). Two questions related to the events that occurred in the story and simply checked children's memory. The other two questions examined children's understanding of the characters' thoughts and beliefs. In total there were 10 ToM questions, two at each order. Zero-order ToM tested factual knowledge about the character, first-order tested knowledge about the character's thoughts, second-order tested knowledge of one character's thoughts about another character's thoughts, and so on.

For each question, children had to decide which of two statements was true (see Appendix 1). For example, after hearing a story about Bob and Johnny who want to play on the school football team, one of the level 2 ToM questions asked which of the following statements was true: a) Johnny doesn't know that the manager wants both him and Bob on the team, b) Johnny thinks that the manager wants both him and Bob on the team.

\section{The Children's Empathy Quotient (EQ-C):}

The EQ-C is a parent-report questionnaire that measures empathy (Auyeung et al., 2009), which was adapted from the adult self-report questionnaire (Baron-Cohen and Wheelwright, 2004). Empathy was assessed because, like ToM, it is related to understanding other people's mental states (see Baron-Cohen and Wheelwright, 2004). Parents were asked to report their level of agreement with 26 empathetic and unempathetic statements concerning their child, on a four-point scale from 'Definitely Agree' to 'Definitely Disagree'. For example, “My child gets upset at seeing others crying or in pain" and "My child is often rude or impolite without realising it". The scale has high internal consistency $(\alpha=.93)$ and good test-retest reliability (.86; Auyeung et al., 2009). 
Metacognition, Empathy, and Child CBT

\section{Wechsler Abbreviated Scale of Intelligence II (WASI-II):}

The two subtests version of the WASI-II (Wechsler, 2011) was used to examine whether general cognitive ability better explains individual differences in children's CBT skills than metacognition and ToM. Children completed the vocabulary and matrix reasoning subtests, which were standardised and totalled to give the Full Scale Intelligence Quotient (FSIQ-2). The FSIQ-2 has excellent internal consistency (.93), excellent test-retest reliability (.87-.95), and very high interrater reliability (.94-.99; McCrimmon and Smith, 2013). The scale has good internal structure, good levels of concurrent validity with other measures of IQ (.71$.92)$, and it distinguishes children with intellectual disability from typically developing children (McCrimmon and Smith, 2013).

\section{Ethical Considerations}

The study was approved by the University of Exeter Ethics Committee (2013/339). All participants provided informed assent with parental consent. Children were rewarded with a certificate for taking part and entered into a prize draw to win one of three $£ 10$ vouchers.

\section{$\underline{\text { Data Analysis }}$}

Analyses were performed in SPSS (IBM, SPSS version 20). Metamemory was calculated by comparing recognition accuracy to feeling-of-knowing judgements for each word-pair.

Specifically, Goodman-Kruskal Gamma correlations (Goodman and Kruskal, 1954) were calculated, using the same method as Wojcik and colleagues (2013). The Gamma statistic is a coefficient with values from -1 to 1 that indicates the strength and direction of the correlation between metamemory judgements and actual memory performance. Stepwise multiple regression was used to test the hypotheses that metacognition and ToM predict children's ability to engage with CBT. One child had missing data and was removed from the analyses in a casewise manner. 
Metacognition, Empathy, and Child CBT

\section{$\underline{\text { Results }}$}

\section{Sample Characteristics}

Means and standard deviations for all of the measures are displayed in Table 1. Age

significantly correlated with ToM, metamemory and recall on the feeling-of-knowing task, and there were no significant gender differences.

Insert Table 1 here.

\section{Metamemory}

To check children's memory for the word-pairs in the feeling-of-knowing task, a one-sample t-test was conducted. This showed that the children's performance was significantly greater than chance, $t(57)=22.53, p<.001$, indicating that children were remembering the word pairs. A repeated measures ANOVA revealed that children believed they would recognise significantly more words $(M=15.84, S D=4.84)$ than they actually did $(M=13.84, \quad S D=2.99)$, $F(1,57)=7.042, p=.01$, suggesting over-confidence. A one-sample $t$-test revealed that Gamma scores $(M=.19, S D=.41)$ were significantly different from zero, $t(57)=3.57, \quad p=.001$, demonstrating that children were able to accurately predict their recognition of non-recalled items. Gamma significantly correlated with the number of words recognised, $r(56)=.22$, $p=.052$, demonstrating that children with greater awareness of the contents of their memory remembered more items.

\section{Theory of Mind}

To check children's memory for the ToM stories, a one-sample t-test was conducted. This showed that children performed significantly better than chance, $t(58)=54.86, \quad p<.001$, indicating that they were remembering the stories. For the ToM questions, one-sample $t$-tests demonstrated that children performed significantly better than chance responding, $t(58)=21.06, p<.001$, which was true at all levels of ToM (all $p<.001)$. Twelve $\quad(20.3 \%)$ participants scored 10 out of 10 , indicating a ceiling effect. 
Metacognition, Empathy, and Child CBT

\section{Linking Thoughts, Feelings, and Behaviours}

On average, children performed highly on the task scoring $69.43(S D=14.05)$ out of $96 . \quad$ To understand which variables predicted children's ability to relate thoughts, feelings, and behaviours, a linear regression was performed using the Stepwise method. Performance on the linking task was the dependent variable and age, empathy, metamemory, IQ, and, ToM were included as independent variables. The analysis revealed that empathy and metamemory significantly predicted children's ability to engage with CBT (see Table 2). This was also true when individual differences in IQ were accounted for in the model. The results imply that children with higher empathy and metamemory performed better on the linking task. ToM did not significantly correlate with performance on the linking task, $r(57)=.19, p=.076$, or empathy, $r(57)=.02, p=.906$.

\section{Insert Table 2 here.}

\section{Discussion}

The aim of this study was to investigate which cognitive and affective capacities predict children's ability to link thoughts to feelings and behaviours; a crucial CBT skill, which may moderate treatment outcomes. Metamemory significantly predicted performance on the linking task, and this remained true when controlling for IQ. This suggests that children with greater metacognitive awareness of the contents of their memory were more able to link thoughts to feelings and behaviours. One explanation is that metamemory and metacognition are associated with executive functions (Mäntylä et al., 2010; Souchay and Isingrini, 2004), which may support the ability to relate thoughts to feelings and behaviours. It is also possible that children with greater awareness of their own mental states have more experience understanding how their thoughts relate to their feelings and behaviours. This metacognitive competency may well be transferrable to the mental states of others, given a basic understanding of people as cognitive entities. However, as only one aspect of metacognition was measured in the present study, it needs to be established whether CBT skills are specifically associated with metamemory or metacognitive awareness more generally. This may be achieved using self-report measures, such as the Metacognitive Awareness Inventory 
Metacognition, Empathy, and Child CBT

(Schraw and Dennison, 1994), parent-report measures, such as the Behaviour Rating Inventory of Executive Functions (Gioia and Isquith, 2011), or other tasks, such as post-task appraisal of difficulty (Krasny-Pacini et al., 2015).

Empathy also predicted performance on the linking task, suggesting that individuals with higher levels of empathy found it easier to understand the feelings of the protagonists in the stories. Simulation theory posits that we understand the mental states of others by projecting ourselves into their situation and employing our own cognitive mechanisms to imagine how we would feel in that situation (Gallese and Goldman, 1998; Goldman, 1989). Indeed, the empathic process of internalising another person's situation and feelings, may subsequently allow understanding of their mental state by employing metacognitive knowledge and skills on that information (Singer, 2006). This is reflected in the empathy and metamemory model, which suggests that children used metacognitive and empathic processes to relate thoughts to feelings and behaviours.

ToM did not correlate with performance on the linking task, which may be due to the ceiling effect observed on the ToM task. The task may have been too easy for 8-11 year old children, meaning that it lacked sensitivity to individual differences in ToM. It may be beneficial to introduce more trials at the higher levels of ToM for children of this age or to request children's justifications for their responses to avoid guessing (e.g. Happé, 1994). Another explanation for the absence of a correlation may be that children did not employ ToM in the linking task. Both the ToM task and the linking task share similar cognitive demands as they require participants to infer other people's mental states. However, the linking task also requires participants to understand people's thoughts in relation to their feelings or actions, and that certain cues can trigger thoughts about previous events. The tasks also differ in their emotional content and demands. The ToM task only requires participants to infer what a character knows or believes, whereas the linking task requires participants to think about a character's thoughts in relation to their feelings and behaviours (note that the behaviours in the thought-to-behaviour stories are also emotionally salient). This may suggest that children relied more on empathic processes to understand emotions and complex mental states, as required in the linking task. Empathy did not significantly correlate with ToM, which may suggest that children used general principles rather than empathy to reason the characters' beliefs or knowledge in the ToM task, in accordance with 'Theory theory' (Gopnik and 
Metacognition, Empathy, and Child CBT

Wellman, 1992). Future research will need to confirm whether children use different cognitive and affective processes for inferring others' emotions, beliefs, and more complex mental states.

The findings of the present study suggest that metacognition and empathy may moderate children's engagement in CBT. An interesting avenue for future research will be to investigate whether these cognitive and affective capacities are associated with treatment outcomes, particularly because they may be underdeveloped in young children and impaired in children with mental health problems (Reynolds et al., 2006). If metacognition and empathy are found to moderate treatment outcomes, then assessment of these capacities could facilitate decisions regarding appropriate treatment. Poor performance on such assessments could indicate that a behaviourally oriented intervention may be more appropriate or that these skills will first need to be developed with the therapist for the child to effectively engage with CBT.

\section{$\underline{\text { Conclusion }}$}

The present study demonstrates that typically developing children aged 8-11 years old are metacognitively aware of the contents of their memory, they can reason other people's mental states to the fourth-order, and they can relate thoughts to feelings and behaviours, which suggests that CBT is typically developmentally appropriate. Metacognition and empathy were found to significantly predict children's ability to relate thoughts, feelings, and behaviours, which may be a critical skill for children to engage with cognitive restructuring in CBT. Therefore, metacognition and empathy may be important moderators of treatment outcomes, which should be investigated in future clinical trials. Clinicians should consider children's metacognition, empathy, and related skills when making decisions about appropriate treatment. 
Metacognition, Empathy, and Child CBT

\section{Implications for policy and practice}

- Typically developing children aged 8-11 years old are metacognitively aware, have an advanced ToM, and can relate thoughts, feelings, and behaviours, suggesting $\therefore a^{+}$CBT is an appropriate treatment for children this age

- Hi... $v$, r, younger children and children with mental health problems may have impan . er in these skills, which could limit the effectiveness of CBT

- In these cr ses, linicians may need to train children's CBT skills or consider more behaviourally $\omega_{\text {if }}$ ate ? treatments 
Metacognition, Empathy, and Child CBT

\section{$\underline{\text { References }}$}

Arnberg, A. and Öst, L.-G. (2014), "CBT for children with depressive symptoms: A metaanalysis", Cognitive Behaviour Therapy, Vol. 43 No. 4, pp. 275-288.

Auyeung, B., Wheelwright, S., Allison, C., Atkinson, M., Samarawickrema, N. and BaronCohen, S. (2009), “The children's empathy quotient and systemizing quotient: Sex differences in typical development and in autism spectrum conditions", Journal of Autism and Developmental Disorders, Vol. 39 No. 11, p. 1509.

Baron-Cohen, S. and Wheelwright, S. (2004), "The empathy quotient: An investigation of adults with Asperger syndrome or high functioning autism, and normal sex differences", Journal of Autism and Developmental Disorders, Vol. 34 No. 2, pp. 163-175.

Crane, R.S., Kuyken, W., Hastings, R.P., Rothwell, N. and Williams, J.M.G. (2010), "Training teachers to deliver mindfulness-based interventions: Learning from the UK experience", Mindfulness, Vol. 1 No. 2, pp. 74-86.

Doherr, L., Reynolds, S., Wetherly, J. and Evans, E.H. (2005), "Young children's ability to engage in cognitive therapy tasks: Associations with age and educational experience", Behavioural and Cognitive Psychotherapy, Vol. 33 No. 2, pp. 201-215.

Esbjørn, B.H., Normann, N. and Reinholdt-Dunne, M.L. (2015), “Adapting Metacognitive Therapy to Children with Generalised Anxiety Disorder: Suggestions for a Manual", Journal of Contemporary Psychotherapy, Vol. 45 No. 3, pp. 159-166.

Fernandez-Duque, D., Baird, J.A. and Posner, M.I. (2000), "Executive Attention and Metacognitive Regulation”, Consciousness and Cognition, Vol. 9 No. 2, pp. 288-307.

Flavell, J.H. (1979), "Metacognition and cognitive monitoring: A new area of cognitivedevelopmental inquiry.", American Psychologist, Vol. 34 No. 10, p. 906. 
Metacognition, Empathy, and Child CBT

Flavell, J.H., Flavell, E.R. and Green, F.L. (2001), “Development of children's understanding of connections between thinking and feeling”, Psychological Science, Vol. 12 No. 5, pp. $430-432$.

Flavell, J.H., Green, F.L. and Flavell, E.R. (2000), “Development of children's awareness of their own thoughts", Journal of Cognition and Development, Vol. 1 No. 1, pp. 97-112.

Gallese, V. and Goldman, A. (1998), "Mirror neurons and the simulation theory of mindreading", Trends in Cognitive Sciences, Vol. 2 No. 12, pp. 493-501.

Gioia, G.A. and Isquith, P.K. (2011), "Behavior Rating Inventory for Executive Functions”, in Kreutzer, J., DeLuca, J., and Caplan, B. (Eds.), Encyclopedia of Clinical Neuropsychology, Springer, New York, NY, pp. 372-376.

Goldman, A. (1989), “Interpretation Psychologized”, Mind \& Language, Vol. 4 No. 3, pp. $161-185$.

Goodman, L.A. and Kruskal, W.H. (1954), "Measures of association for cross classifications", Journal of the American Statistical Association, Vol. 49 No. 268, pp. $732-764$.

Gopnik, A. and Wellman, H.M. (1992), "Why the child's theory of mind really is a theory", Mind \& Language, Vol. 7 No. 1-2, pp. 145-171.

Grave, J. and Blissett, J. (2004), "Is cognitive behavior therapy developmentally appropriate for young children? A critical review of the evidence", Clinical Psychology Review, Vol. 24 No. 4, pp. 399-420.

Happé, F.G.E. (1994), “An advanced test of theory of mind: Understanding of story characters' thoughts and feelings by able autistic, mentally handicapped, and normal 
Metacognition, Empathy, and Child CBT

children and adults", Journal of Autism and Developmental Disorders, Vol. 24 No. 2, pp. $129-154$.

Hart, J.T. (1965), “Memory and the feeling-of-knowing experience.”, Journal of Educational Psychology, Vol. 56 No. 4, p. 208.

James, A.C., James, G., Cowdrey, F.A., Soler, A. and Choke, A. (2015), “Cognitive behavioural therapy for anxiety disorders in children and adolescents", Cochrane Database of Systematic Reviews, No. 2.

Koriat, A. (1993), "How do we know that we know? The accessibility model of the feeling of knowing.", Psychological Review, Vol. 100 No. 4, p. 609.

Krasny-Pacini, A., Limond, J., Evans, J., Hiebel, J., Bendjelida, K. and Chevignard, M. (2015), "Self-awareness assessment during cognitive rehabilitation in children with acquired brain injury: A feasibility study and proposed model of child anosognosia", Disability and Rehabilitation, Vol. 37 No. 22, pp. 2092-2106.

Lai, E.R. (2011), “Metacognition: A literature review”, Pearson's Research Reports, available at http://www.pearsonassessments.com/hai/images/tmrs/Metacognition_Literature_Review _Final.pdf (accessed 1 Decemeber 2012).

Liddle, B. and Nettle, D. (2006), "Higher-order theory of mind and social competence in school-age children", Journal of Cultural and Evolutionary Psychology, Vol. 4 No. 3-4, pp. 231-244.

Mäntylä, T., Rönnlund, M. and Kliegel, M. (2010), “Components of executive functioning in metamemory", Applied Neuropsychology, Vol. 17 No. 4, pp. 289-298. 
Metacognition, Empathy, and Child CBT

McCrimmon, A.W. and Smith, A.D. (2013), "Review of the Wechsler Abbreviated Scale of Intelligence, (WASI-II)”, Journal of Psychoeducational Assessment, Vol. 31 No. 3, pp. $337-341$.

Nelson, T.O. (1990), "Metamemory: A theoretical framework and new findings", In Bower G. H. (Ed.), Psychology of Learning and Motivation, Vol. 26, Academic Press, New York, NY, pp. 125-173.

Nelson, T.O. and Narens, L. (1980), "A new technique for investigating the feeling of knowing”, Acta Psychologica, Vol. 46 No. 1, pp. 69-80.

Premack, D. and Woodruff, G. (1978), "Does the chimpanzee have a theory of mind?", Behavioral and Brain Sciences, Vol. 1 No. 4, pp. 515-526.

Quakley, S. (2001), "An Investigation into Children's Developing Ability to Identify and Link Thoughts, Feelings and Behaviours: Implications for Cognitive Behaviour Therapy for Children", PhD Thesis, The University of East Anglia, Norwich, England Quakley, S., Coker, S., Palmer, K. and Reynolds, S. (2003), “Can children distinguish between thoughts and behaviours?", Behavioural and Cognitive Psychotherapy, Vol. 31 No. 2, pp. 159-168.

Quakley, S., Reynolds, S. and Coker, S. (2004), “The effect of cues on young children's abilities to discriminate among thoughts, feelings and behaviours", Behaviour Research and Therapy, Vol. 42 No. 3, pp. 343-356.

Reynolds, S., Girling, E., Coker, S. and Eastwood, L. (2006), “The effect of mental health problems on children's ability to discriminate amongst thoughts, feelings and behaviours", Cognitive Therapy and Research, Vol. 30 No. 5, pp. 599-607. 
Metacognition, Empathy, and Child CBT

Schraw, G. and Dennison, R.S. (1994), “Assessing metacognitive awareness”, Contemporary Educational Psychology, Vol. 19 No. 4, pp. 460-475.

Singer, T. (2006), "The neuronal basis and ontogeny of empathy and mind reading: Review of literature and implications for future research", Neuroscience \& Biobehavioral Reviews, Vol. 30 No. 6, pp. 855-863.

Souchay, C. and Isingrini, M. (2004), “Age related differences in metacognitive control: Role of executive functioning”, Brain and Cognition, Vol. 56 No. 1, pp. 89-99.

Stallard, P. (2002a), Think Good-Feel Good: A Cognitive Behaviour Therapy Workbook for Children and Young People, John Wiley \& Sons, Chichester, England.

Stallard, P. (2002b), "Cognitive behaviour therapy with children and young people: A selective review of key issues", Behavioural and Cognitive Psychotherapy, Vol. 30 No. 3, pp. 297-309.

Watanabe, N., Hunot, V., Omori, I.M., Churchill, R. and Furukawa, T.A. (2007), "Psychotherapy for depression among children and adolescents: A systematic review", Acta Psychiatrica Scandinavica, Vol. 116 No. 2, pp. 84-95.

Wechsler, D. (2011), Wechsler Abbreviated Scale of Intelligence - Second Edition, Pearson, San Antonio, TX.

Wells, A. and King, P. (2006), "Metacognitive therapy for generalized anxiety disorder: An open trial”, Journal of Behavior Therapy and Experimental Psychiatry, Vol. 37 No. 3, pp. 206-212.

Wimmer, H. and Perner, J. (1983), "Beliefs about beliefs: Representation and constraining function of wrong beliefs in young children's understanding of deception”, Cognition, 


\section{Metacognition, Empathy, and Child CBT}

Vol. 13 No. 1, pp. 103-128.

Wojcik, D.Z., Moulin, C.J.A. and Souchay, C. (2013), "Metamemory in children with autism: Exploring 'feeling-of-knowing' in episodic and semantic memory.”, Neuropsychology, Vol. 27 No. 1, p. 19. 
Metacognition, Empathy, and Child CBT

\section{Appendix 1: Example Statements of the ToM Task at Each Level}

ToM Level 0:

a) Bobby's favourite thing in the world is chocolate.

b) Bobby's favourite thing in the world is going out with his friends.

ToM Level 1:

a) Bobby thinks his chocolate is in his mum's shopping bag.

b) Bobby thinks his chocolate is in his cupboard.

ToM Level 2:

a) Johnny doesn't know that the manager wants both him and Bob on the team.

b) Johnny thinks that the manager wants both him and Bob on the team.

ToM Level 3:

a) The manager thinks that Johnny knows he wants him to be on the football team.

b) The manager knows that Johnny doesn't know that he wants him to be on the team.

ToM Level 4:

a) Ben thinks that Anna believes that he knows that Mum wants perfume for her birthday.

b) Ben thinks that Anna knows that he knows that mum wants flowers for her birthday. 
Figure 1.

An Example of the Thought-Behaviour Picture and Story Stimuli (adapted from Quakley etal.,

2004)

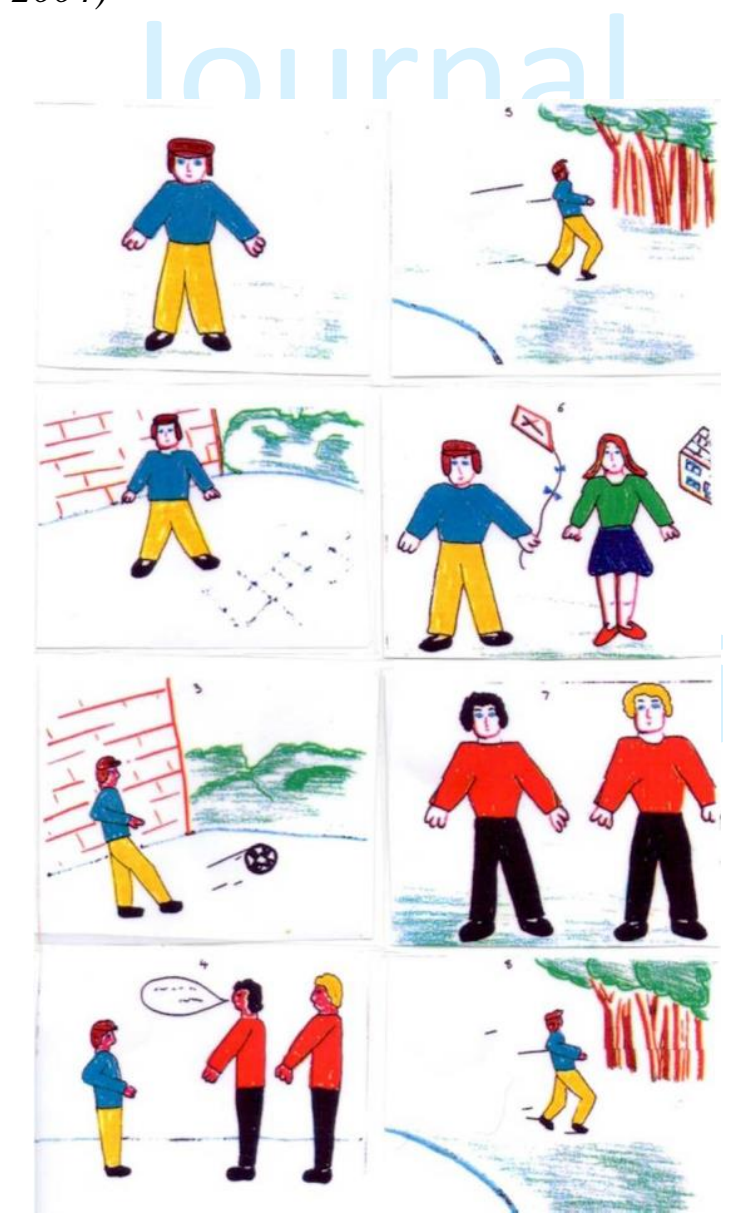

\section{Thought to Behaviour. Sad. Male}

Put picture 1 down

Say: This is Ben

Put picture 2 down

Say: This is Ben's playground in his new school

Put picture 3 down

Say: One day Ben was playing in his new playground

Put picture 4 down

Say: When some big boys in red coats came over and called Ben names

Put picture 5 down

Say: Ben ran away to hide

Say: Why did Ben run away to hide?

Put picture 6 down

Say: Many days later, Ben was playing with his friend Clare

Put picture 7 down

Say: When Ben saw the big boys in red coats

Put Picture 8 down

Say: Ben Ran away to hide

Say: Why did Ben run away to 't-te right now? 
Table 1.

Descriptive Statistics, Correlations with Age and Comparisons between Gender Groups

Linking Task

\begin{tabular}{cccc}
\hline$M$ & $S D$ & Age $(r)$ & Gender $(t)$ \\
\hline 69.43 & 14.05 & .20 & 1.43
\end{tabular}

Empathy

40.66

6.86

.08

.52

False-Belief:

Memory

9.68

.66

.11

.79

Theory of Mind

8.42

1.25

$.25 *$

.81

Feeling-of-Knowing:

Recall

1.66

1.58

$.23 *$

.11

Recognition Memory

13.84

2.99

.14

.07

Yes Judgments

15.84

4.84

.01

1.82

Gamma

.19

.41

$.34 * *$

.77

WASI-II:

FSIQ-2

108

12.7

N/a

1.55

Vocabulary

57.78

8.66

N/a

.60

Matrix Reasoning

51.66

9.85

$\mathrm{N} / \mathrm{a}$

1.84

Note: Scores on the WASI-II are standardised for age. $* \mathrm{p}<.05, \quad * * \mathrm{p}<.01$ 
1

2

3

4

5

6

7

8

9

10

11

12

13

14

15

16

17

18

19

50

51

53

55

56

57

58

59

60

Table 2.

Results of the Regression Analyses for Performance on the Linking Task

\begin{tabular}{|c|c|c|c|c|c|c|c|}
\hline Model & $R^{2}$ & $F$ & $p$ & Predictors & $\beta$ & $t$ & $p$ \\
\hline \multirow[t]{2}{*}{1} & & 4.84 & .012 & Empathy & .29 & 2.35 & .022 \\
\hline & & & & Metamemory & .26 & 2.08 & .042 \\
\hline \multirow[t]{3}{*}{2} & .15 & 3.21 & .030 & Empathy & .28 & 2.06 & .044 \\
\hline & & & & Metamemory & .26 & 2.08 & .043 \\
\hline & & & & IQ & .04 & .33 & .743 \\
\hline
\end{tabular}

